\title{
Effects and Benefits from ISO Certification in Albanian Businesses
}

\author{
Dr. Ira ZOGA (GJIKA) \\ ShLP "Mesdhetare" Tirana, ALBANIA \\ Dr. Nikollaq PANO \\ ShLP "Mesdhetare" Tirana, ALBANIA
}

\begin{abstract}
The main purpose of this paper is to examine the influence of ISO standards implementation in Albanian companies, through evidence of expected benefits and the actual ones at the framework of a company. The analysis is based on a theoretical overview of the advantages and results expected to derive from the certification, according to the abundant literature of the last decade. From the other side, the empirical study of a group of Albanian companies ISO certified constitutes the background of the real analysis that indicates the achieved results from the companies' viewpoint. There are done efforts to assess and measure the quantitative and qualitative contribution of standards on the performance of manufacturing and service companies. Further on, the paper verifies that all companies do report benefits from the certification, although they are of variable types. The paper concludes with some suggestions about measuring of certification' effects on the performance of companies, as well as revealing of factors that can contribute to a higher profitability of Albanian companies during the implementation of ISO 9000 normative. The authors intend to bring a modest contribution and encourage further studies on the field, closely related to the characteristics of Albanian businesses.
\end{abstract}

Keywords: ISO 9000, quality management, benefits from certification, performance.

\section{Introduction}

Since its introduction in 1987, the ISO 9001 series for quality norms has been propagated in all continents. After several years of preparing the structure and infrastructure necessary for the certification, this process began in 1993, with more than $80 \%$ of the certificates during the first year issued in Europe. Currently there is a total of 1.138 .155 ISO 9001 certificates issued in the world, $42.5 \%$ of which in Europe (ISO Survey 2014). Quality management became a business practice to the benefit of companies, with a gradual positive effect on the respective industry and even further. Nowadays a worldwide trend towards increasing customer's expectations regarding quality can easily be noticed. This tendency goes hand in hand with a growing awareness that continuous quality improvements are often necessary in order to achieve and sustain outstanding economic performance. The competition among companies in a developing market, and even among countries, plays a decisive role in improving quality management system strategies; experience from countries with some history in elaborating strategies is forwarded to countries with developing economies. The current economic-technological scenario imposes the need for continuous changes upon organizations, in the way they operate and manage their business, in order to adjust themselves to newer realities and to remain competitive (Oliveira, Serra, 2010). Albania is among those countries that have denoted advances in terms of involving quality management systems and embracing quality certification procedure while paving the road towards a consolidated market economy. There were 171 companies in Albania that have obtained ISO 9001 certificates by the end of 2014 , the first one having been issued in 2000 . A considerable increase was seen from 2009, as shown (Fig.1) (ISO Survey 2014). 


\section{Evolution of ISO 9001 certificates in Albania}

$$
\text { Select a country Albania }
$$



Figure 1 - ISO 9001 certification in Albania. Source: Data from the ISO series (2014)

From a theoretical point of view and due to its intrinsic goal, an ISO 9001 quality management system:

- $\quad$ communicates that the company provides products and services of consistent quality;

- $\quad$ shows that products and services provided by the company meet the customer's requirements, comply with the law and legislation, and meet the organization's own requirements;

- $\quad$ can help the company streamline its business processes and continuously improve them.

Additionally, companies can take advantages of such standard implementation, like:

- $\quad$ ISO 9001 helps increase customer satisfaction;

- ISO 9001 is overall positive for the company image, demonstrating that it complies with internationally recognised quality standards. This is often a requirement for customers and suppliers to do business in a quality oriented entrepreneurial environment.

The ISO 9001 standard is not the only recognized, accepted, and implemented standard in Albania. Other standards the Albanian companies comply with and have been certified accordingly mostly include environmental standards, food safety standards, energy management ones, etc. (Fig.2).

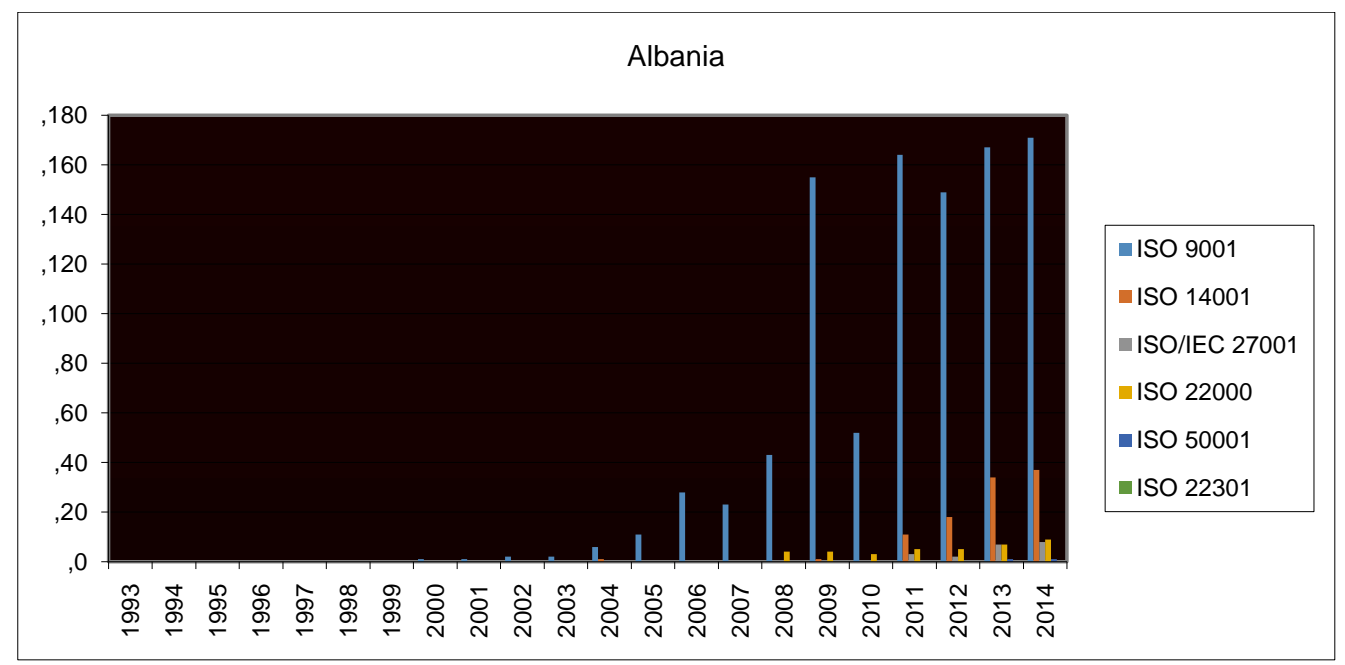

Figure 2 - Trend of ISO certification in Albania. Source: Data from the ISO series (2014) 
Considering the number of companies registered and carrying out activity in Albania during the same period of time, as classified by legal forms, there is evidence of a relatively low fraction of companies equipped with an ISO 9001 certificate. Only about $1 \%$ of the 29.000 companies registered as juridical persons in Albania are certified by the end of 2015 . Meanwhile, an empirical study of Albanian companies regarding their competitive strategies and the utilization of the information on their websites confirms an increased awareness in many companies regarding the role quality management plays and the competitive advantage it provides (Bitzenis, 2005), (Shkurti, 2013). This deviation promotes studying what factors stimulate ISO 9001 certification in Albanian companies, as well as what its benefits are. This analysis is only limited to this standard because: - it is the most well-known and most popular standard in Albania and worldwide; - its implementation is directly linked to company performance, as proved by various studies; - the principles ISO 9001 is based on serve as basis for other standards, and consequently an analysis of the stimulating factors and benefits of ISO 9001 certification may aid similar analyses of other standards in the future.

The large number of publications in academic literature about quality management systems in general and of standards specifically is an indirect sign of the popularity and the interest they have aroused. Some of the more relevant concerns are founded on the following points: (1) analysis of the motivation for certification; (2) analysis of the benefits of certification, the evolution of organizations, perceptions of such benefits, and advantages/ disadvantages of certification; (3) the impact of quality certification on an organization, and company finance; (4) the possibility for integration and/or competition between quality certification and TQM, and (5) analysis and preview of the diffusion of certification (Peixe et al., 2012).

Although dozens of scientific studies on ISO 9001 have been published to date, a confusing picture of the impact of ISO 9001 on financial performance remains. While many have concluded that ISO 9001 implementation and certification had a direct and positive financial impact, others found no significant effect. Beyond the direct link between the QMS and financial success, some studies highlighted other variables that may have an influence (Poksinka, 2010). This work is an effort to identify a relationship between a company's internal forces pushing for the application of quality management systems and external market forces or governmental regulations that obligate such a thing within the Albanian business environment.

\section{Purpose and objectives of the study}

The use of standards and the benefits of standardization have drawn the attention of researchers, bringing a significant number of studies about these topics. However, as the last publications from International Organization for Standardization emphasize, comparing these studies and reaching overall conclusions is difficult because they were carried out by different organizations, with different objectives and using different methodologies (ISO, 2013). Most of them followed a macroeconomic perspective, trying to evaluate the contribution of standardization to the economic performance of countries, considering indicators such as GDP growth and productivity increase. Those studies made substantial progress in understanding the economic impacts of standards. However, they have not, or have only marginally, addressed the microeconomic perspective, and they have not tried to assess the benefit that standards bring to individual companies. In order to fill this gap, the organization itself has presented the ISO Methodology, which provides a systematic approach for assessing the economic benefits of standards for individual organizations. It supports companies' internal analyses, the development of case studies and the comparison of results from different studies. The primary scope of the ISO Methodology is assessing the economic benefits of standards (i.e. the contribution of standards to the creation of economic value) for a company. The methodology can be applied to the economic impact of standards on an industry sector at national or international level, although this requires particular attention and increased efforts (ISO, 2013).

Small businesses and very small businesses make up $82 \%$ of functional companies within the structure of actively functioning companies in the Albanian market (Table 1), and only $18 \%$ of them have similar organizational and management characteristics with those competing in the European market. This significantly limits massive use of quality management systems in the Albanian market and is one of the main limiting factors of this study. The ISO certification target group, and subsequently this study's target group, are companies classified as juridical persons. Another difficulty in conducting this study is the lack of previous empirical studies in this filed, based on protocols dictated by global experience, and difficulties in employing methodologies suggested by them. These factors, as well as other minor ones, have conditioned our study and have oriented us to determine the main purpose of it as follows:

- investigation of factors that motivate the implementation of ISO standards in Albanian companies; 
- assessment of the impact these standards have, through evidence of expected benefits and the actual ones inside companies.

A company typically seeks certification when: (1) it feels compelled to do so for economic reasons or market-based demands; (2) it possesses a high capacity and the necessary competencies to obtain such certification; (3) it possesses adequate knowledge of the norm, of the impacts of its activities (internal and external), and identifies certification to be a strategic action for the company (Melnik et al, 2003)

This attestation pushes toward a comparison, for balancing purposes, between chances the external environment offers and strengths the company itself posseses. However, there is academic consensus concerning motives towards implementing Quality Management System (QMS), which seems motivated among the majority of organizations by external factors such as market pressure and an interest to improving the company's image. Other organizations are especially motivated by internal factors, such as improved products or services, reduced costs associated to a lack of quality and improving the company's internal efficiency (Casadesus, Heras, 2005, Shannon, Robson, Sale, 2001). They are mostly oriented by and trying to take advantage of their strengths and developing them further supported by strategic decisions.

Internal or external motivation might be one of most inspected and influential factors to explain the different outcomes of the various studies, and the differences between the performance improvement companies observe. We share the popular academic idea that motivation and internalization are the two most discussed variables which organizations should take into consideration when implementing ISO 9001.

First of all, the motivation for implementing ISO 9001 can influence its effect on financial performance. Organizations may wish to obtain certification for external reasons such as pressure from customers, markets or governments, or for internal reasons such as improving productivity and efficiency. Those applicants targeting short-term external benefits could expect to gain mainly external benefits, while those aiming at real quality improvement could expect to achieve higher overall benefits. That being said, the first objective of this study and this paper is determining the most influential factors in prompting companies for ISO certification.

Secondly, the degree to which ISO 9001 principles are adopted internally is dependent on the motivation of the organization, and is thought to be critical to successful implementation. Organizations with external motivation tended to implement measures prescribed by the standard as a quick fix to quality problems, while those with internal motivation were more likely to use the standard and the underlying principles in day-to-day decision making to really improve quality (Poksinka, 2010). Internalization of ISO 9001 principles is considered necessary in achieving the most significant performance benefits from the QMS standard. Our study' second objective is identifying companies' expectations about the benefits of certification.

Assessing the advantages companies have had as a result of certification, from their point of view, is the third objective of the study, which, combined with previous objectives, allows for the deduction of some recommendations to help companies for the best use of standards. The emphasis should be on the quality management principles the most recent ISO 9001:2015 standard is constructed around, that are: customer focus, leadership, engagement of people, process approach; improvement; evidence-based decision making; relationship management (ISO 9001:2015).

\section{Research question and methodology}

The strong relationship between certification motivations and resulting benefits for Albanian companies is at the focus of this paper. When firms are reacting to external pressure for certification, they may face ISO 9001 registration as the prime objective and adopt a minimalist approach to achieving it. Such firms obtain quality certification, but they may not fully value quality management systems, and thus will achieve limited benefits (Sampaio et al., 2009).

The research questions we put forward are:

- What are the main factors that prompt Albanian companies toward ISO 9001 certification?

- Do Albanian companies' actual effects of certification match their expectations?

To answer these question, we took up a research project looking at ISO 9000 set of standards in a more integrated manner using the different research strategies. Both questionnaire surveys and case studies investigating the processes related to 
standard implementation and operation in the organizational settings were used. The worth of ISO 9001 differs between organizations and depends on several organizational and external conditions, such as motivation for standards implementation, maturity level of quality management, implementation strategy, certification audits, and involvement of people. Due to this, benefits achieved from ISO 9001 are not the same for every organization.

To carry out this study, we picked 50 companies that had gone through the process of certification at different times between 2005 and 2014. This choice was limited by the fact that most ISO certified Albanian companies have received certification after 2009. The questionnaire survey that was sent to these companies was constructed with the purpose of evaluating the degree of interest Albanian companies have in ISO certifications for their systems by looking at the effects this system's application has had on certified companies that employ it. The companies included in this study conduct their activity in different fields, as the structure of ISO 9001 certified companies by field of activity is also very diverse. Surveyed companies' activities include firms from metal industry, meat processing, food and drinks, wholesale/ retail and services. The limited number and size of certified companies does not allow for an in-depth, discipline-oriented, or size-specific study. The prevalence of medium and small companies in the Albanian economy has oriented our research toward assaying companies with various annual turnovers and numbers of employees.

These are at the same time some of the limitations of our study.

The questionnaire is made in accordance with the formal rules of questionnaire construct and it has been based on implemented, estimated and protocolled elements in studies previously done in different countries. The intention was to avoid confusion and bias, to get the most accurate and not -influenced answer from the respondents.

The questionnaire is composed of three parts. The first one intends to evidence the company profile and potential changes during the years of ISO standard implementation, from the economic aspect and market positioning. The main concern is to collect the information that would permit estimation of the company activity, size and growth during those years, especially on the last ones.

The construct of the second part enables to reveal and assess the factors that stimulate the companies toward certification, as well as expected results from this process. The value of ISO 9000 differs among organizations and depends on several organizational and external conditions, such as motivation for ISO 9000 implementation, maturity level of quality management, implementation strategy, involvement of people, and certification audits.

ISO 9000 is still implemented mostly because of customer requirements and the certificate is the most desired outcome of implementing a quality management system. The certification to ISO 9001:2000 is a must in today's business environment. In fact, the certificate gives no competitive advantages, but gives a competitive disadvantage for organizations which are not certified. With this in mind, we want to reveal and estimate what actually happens in Albanian businesses, that can be done by information this part of questionnaire provides.

The third part is designed to envision directly the implementation of ISO system, from the operational and financial point of view, from the human resource management effects, and to enable the comparison of expected with actual benefits from the system implementation. ISO 9000 offers organizations the capability to develop and implement an effective and dynamic quality management system with a focus on continual improvement, but the certification itself doesn't ensure that an organization achieves sustained competitive advantages. The key to the success is the willingness and the depth to which an organization desires to go in satisfying the standard's requirements or fulfilling their own improvement needs. However, organizations often lack internal motivation to work with the QMS. Those organizations devoting too much attention and placing too much value on the certificate would not be able to realise the full potential of ISO 9000.

The third part of the questionnaire aims to assess how well the system is implemented and how it works in the company, considering the difficulties and limitations the company faces with.

\section{Discussion and analysis}

The empirical study of a group of Albanian companies ISO 9001 certified forms the basement for the analysis of achieved results. The profile of the sample is characterized as follows:

1. There are included in the study 50 companies that have received the ISO 9001 certificate after 2005 and 45 of them have given valid responses. 
2. The sample of the responding companies includes private companies from a variety of sectors: around $35 \%$ are food and beverage manufacturing companies, around $30 \%$ from construction, another $30 \%$ from wholesale/ distribution \& retail, while the difference are service companies (banking/finance, consultancy, communications, insurance). Such structure of the sample implicits similar motivation factors and results from ISO 9001 implementation, unless otherwise clearly evidenced and discussed.

3. After collecting the filled in questionnaire, 12 companies were selected for interviews with the quality managers respeonsible for the system implementation in the respective companies. The increasing turnover and number of emplyees during last years were the main criteria for the selection.

4. The most of respondent companies have been doing business for more than 10 years. Only two of companies were established recently, but their development justifies considering them as part os the sample and rely on their responses. All the companies filled in the questionnaires voluntarily and without being influenced.

5. The surveyed companies have their activity throughout the country and some of them are also involved in export.

\subsection{Motivation factors and implications}

There are companies that have always worked to high standards and they knew that, but they want their clients know and understand it too. From the other side, companies are attempting to gain and work with new and/ or larger clients, that in turn are requesting audited proof of company' methods and standards of practice. This happens when companies became ISO 9001 certified, because these standards not only help them to comply with regulations - in conjunction with third-party certification by an accredited certification body -, they also help companies demonstrate to potential customers and authorities that they are doing things according to the rules and providing quality products or services.

The answers from the Albanian companies in the survey rank the factor "to satisfy the external requirements and the market pressure" in the first place, with around $60 \%$ of respondents accepting that they have been driven by such needs. Further discussion of this factor shows that a number of companies have gone through with the certification process in order to extend their activity to foreign markets by adapting to export requirements for their products. This was more typical for companies that manufacture food products, drinks, shoes, etc. The rest of the companies that have given in to market pressure mention ISO certification as a requirement for participation in public procurement procedures. From many companies' point of view, ISO 9001 certification allows them to enter the public market, which in turn helps to maintain good customer relations, increase business confidence, output and profit.

The second-ranked factor by certified companies is "to facilitate procedures and contracting with clients". About $20 \%$ of surveyed companies confirm that ISO 9001 certification was mostly needed in order to facilitate selection procedures from clients and to contract with them. In Albania's case, following years of continuous effort to attract direct foreign investments, this demand is closely tied to the demands foreign companies put forward and the work practices they aim to impose in the business environment during their cooperation with Albanian companies. Some of the less stimulating factors were "to improve productivity, the organization \& operation of actual QMS" and "to improve the image and the reputation of the company". These factors were generally viewed as ISO certification benefits for SMEs, rather than as promoters to undertake the whole process.

Based on the results of the questionnaire surveys and the interviews with managers of respective companies, we can answer the first question posed in this study by confirming that the main certification stimulating factors are external and tied to export demand, participation in public procurement, and facilitation of client contracting. Increased awareness of many companies' leaders regarding quality as one of the most important competitive advantages to be successful in the market is worth noting from the results of the first part of the survey. Nevertheless, taking definite steps towards the establishment of quality management systems and confirming the realization of these systems' requirements, which materializes in the form of the corresponding certificate, is considered unnecessary or difficult. This is considerably due to companies' expected benefits from a certification process, which has its costs, and requires time and organizational commitment. 


\subsection{ISO 9001 certification and the organization performance}

There are evidences that the performance of organizations can be affected by ISO 9001 certification. Without going into details of classifications done for the expected benefits from certification, well discussed in many studies (Tari et al. 2012), we have firstly listed the benefits Albanian companies would expect to achieve from the certification based on their general knowledge, the presentations from consultancy entities and their partner experience. Such benefits include:

help to improve the quality of goods and services; help to drive growth, cut costs and increase profits; sharpen the business processes and increase efficiency; enhance the credibility and secure customer confidence; give a competitive edge to the business; open up export markets for goods and services; open doors to new customers and strengthen existing business; help to compete with bigger enterprises; strengthen your marketing pitch; help to comply with regulations.

Despite being mostly stimulated by external factors, the Albanian companies rank improving the company's image first when considering expected effects of the system's implementation. Next are using the certification as a marketing tool to give them advantage over competitors, and sales growth, on the condition that the added income be able to cover certification expenses as fast as possible.

The results from the third part of the survey allow us to make a qualitative assessment of the factual benefits Albanian companies have attained following certification. Increased participation in public procurement, which means an increase in sales and market expansion to companies, is the most important accepted effect. A quantitative assessment of the benefits of this nature hasn't been possible in the context of this study, as it would require a longitudinal observation of the companies, and the selection of companies with specific characteristics. The increase of exports and cooperation with foreign investors, as well as the improved relationship with authorities and other stakeholders, constitute significant external benefits.

As for internal benefits, various authors' studies have suggested that certified companies can obtain better productivity, have lower defect rates and fewer customer complaints (Sun, 2000). Another study (Nield \& Kozak, 1999) has suggested that the standard implementation might have the following benefits: operational benefits (improved operating systems, enhanced operating practices), human resources benefits (gained more committed work force, reduction in staff turnover), and marketing benefits (improved customer satisfaction, gained competitive edge, nation-wide recognition). However, these benefits are less apparent and less perceptible in Albanian companies, at least compared with marketing benefits (improved customer satisfaction, gained competitive edge, nation-wide recognition).

We emphasize the opinion that there is a positive relationship between ISO 9001 certification and performance, but the benefits achieved from ISO 9000 set of standards are not the same for every organization. They depend on the level of ambition and commitment to achieve business excellence. There are only a few external and internal benefits that follow from the standard itself. Most internal benefits require a change in practice and commitment from all organizational members. Our study, through its case-study part, the interviews with the responsible quality managers, proves that the implementation of system requirements is easier and more effective in those companies where top management is committed to engage in and support the certification process. Regardless of this, the concern for the extra cost required and the complaint for the extra documentation/ bureaucracy augmented due to system requirements is one of the most unsatisfactory finding evidencedin the study.

\section{Conclusions}

This paper highlights and analyses the conditions under which ISO 9001 certification is likely to be implemented and to have positive effects on organizational, marketing and financial performance in Albanian companies. Using the different research strategies and theoretically integrating the results from other related studies, this paper is providing a more comprehensive picture on ISO 9001 motivation factors and standartization advantages.

Some conclusions are drawn at the end of the study work according to the results of the questionnaires and face to face interviews in 12 companies with quality managers. In response to the first research question and fulfilling the first objective of our work is determining the most influential factors in prompting companies for ISO certification, the following points should be mentioned: 
- The Albanian companies have been stimulated mainly from external factors to apply for and successfully get the certificate ISO 9001. The internal factors are ranked lower in the list.

- Amongst the exteral motivation factors, almost at the same level are ranked the certification as a requirement for participation in public procurement procedures, which in turn brings a fast increase of sales and profit; the certification as a need for export, especially for food and beverage manufacturing.

- Implementation of ISO standard derived as a need from the internal factors is mainly related to the improvement of operation, cost reduction and decreasing nonconformities. The image improvement and reputation is the least influential factor, as per Albanian companies viewpoint.

Regarding the 2-nd research question raised and the objectives related - what are the actual benefits of certification and do they match with the companies' expectations - the following points are of importance:

- The companies that have had sales growth due to greater participation in public tenders and due to entry in export markets confirm financial and marketing benefits from certification, as they expected. Measuring such effect and assessing the role of certification in it compared to other factors might be a field of investigation for future studies.

- The companies that have started the process and implemented the ISO system with the expectancies for service quality improvement, for marketing needs and better image of the company, confirm achieving of such benefits, but they don't evidence cost reduction, and/or financial results as expected.

- A few companies have been implementing the system for several years without any obvious result, especially in finacial and operational terms. However, these cases might need a detailed analysis, beyond the capability of the mentioned study.

Practical implications for Albanian companies - The internal motivation and design of the QMS based on the real needs of an organization are important conditions to achieve positive effects from the standards implementation. The focus should be on the areas that need to be improved, not only on fulfilling the minimum requirements for obtaining the certicate. The objectives need to reflect the expectations of customers as well as the organization's aims for future success. Consequently, only self-motivation will make improvement sustainable. If the ambition and commitment level are very low and organizations devote too much attention and place too much value on the certification, the focus on real improvements is shifted away by limiting the efforts to the satisfaction of the minimum necessary requirements, just fulfilling the auditors' demands and setting defensive and easy to achieve objectives.

Furthermore, the involvement of people was identified as critical for the successful implementation and operation of a quality management system. The commitment of top management is vital, as well as the engagement of a dedicated and knowledgeable quality manager or facilitator.

This work could have been of value if it would encourage further studies on the field, closely related to the characteristics of Albanian businesses.

\section{Bibliography}

[1] Almeida M., Caten C., Gutterres M., Evaluating ISO 9001:2000 Certified and Non-Certified Organizations in Brazilian Leather-Footwear Chain, Brazilian Journal of Operations \& Production Management Volume 6, Number 2, 2009

[2] Bitzenis A., Obstacles to entrepreneurship in a transition business environment: The case of Albania, JOURNAL OF SMALL BUSINESS AND ENTERPRISE DEVELOPMENT · JULY 2005

[3] Carlin W., Landesmann M., From Theory into Practice? Corporate Restructuring and Economic Dynamism in Transition Economies, 1997

[4] Casadesus M., Gimenez G., Heras I., "Benefits of ISO 9000 implementation in Spanish industry", European Business Review, Vol. 13 Iss: 6, 2001.

[5] http://www.instat.gov.al/al/themes/regjistri-statistikor-i-nd\%C3\%ABrmarrjeve.aspx

[6] ISO - Economic benefits of standards ISO methodology 2.0 - 2013 
[7] Manders B., Implementation and Impact of ISO 9001, 2015, ERIM reference number: EPS-2014-337-LIS

[8] Peixe B., Trierweiller A., Bornia A., Tezza R., Campos L., Worldwide Evolution of ISO 9001 and 14001 Certified Companies: an Exploratory, Comparative Ten-Year Study - ICIEOM 2012 - Guimarães, Portugal

[9] Piskar F., The Impact of the Quality Management System ISO 9000 Managing Global Transitions 5 (1), 2007

[10] Poksinska B., When does ISO 9000 lead to improvements? 2010, International Journal of Productivity and Quality Management, (5), 2.

[11] Psomas E., Pantouvakis A., Kafetzopoulos D., The impact of ISO 9001 effectiveness on the performance of service companies Managing Service Quality Vol. 23 No. 2, 2013

[12] Sampaio P., Saraiva P., Rodrigues A., CASE STUDY APPROACH TO THE ECONOMIC EVALUATION OF ISO 9001 CERTIFICATION, 2012

[13] Sconosciuto L., Building a more competitive private sector in Albania, EBRD website, Apr 2015

[14] Shkurti L., Strategy Implementation Challenges in Albanian Organizations, European Journal of Business and Management, Vol.5, No.28, 2013

[15] Tarí J., Molina-Azorín J., Heras I., Benefits of the ISO 9001 and ISO 14001 standards: A literature review, 2012

[16] The ISO Survey of Management System Standard Certifications - 2014 Executive summary.

Table 1. Active enterprises by legal form, end of year 2015. Source: INSTAT, 2016

\begin{tabular}{|l|l|l|l|l|}
\hline \multirow{2}{*}{ Forma ligjore } & \multirow{2}{*}{$\begin{array}{l}\text { numër } \\
\text { number }\end{array}$} & $\begin{array}{l}\text { Pronare / administratore femra } \\
\text { Female owner / administrator }\end{array}$ & \multirow{2}{*}{ Legal Forms } \\
\cline { 3 - 5 } & & $\begin{array}{l}\text { numër } \\
\text { number }\end{array}$ & $\%$ & \\
\hline & & & & \\
\hline Gjithsej & 152,288 & 47,706 & 31.3 & Total \\
\hline Fermerë & 19,543 & 1,564 & 8.0 & Farmers \\
\hline Persona Fizikë & 103,414 & 40,208 & 38.9 & Physical persons \\
\hline Persona Juridikë & 29,331 & 5,934 & 20.2 & Juridical persons \\
\hline Shoqëri me Përgjegjësi të Kufizuar & 23,643 & 4,356 & 18.4 & Limited Liability Companies \\
\hline Shoqëri Aksionare & 911 & 145 & 15.9 & Joint Stock Companies \\
\hline Ndërmarrje Shtetërore & 935 & 296 & 31.6 & Public Enterprises \\
\hline Administrata Publike & 498 & 87 & 17.5 & Public Administration \\
\hline OJF, Org. ndërkombëtare & 2,410 & 861 & 35.7 & NGO, Intern. Organization \\
\hline Shoqëri të tjera & 934 & 190 & 20.3 & Other Companies \\
\hline
\end{tabular}

